\title{
AS MULHERES NOS RELATOS DOS VIAJANTES ESTRANGEIROS NO SÉCULO XIX NA PROVÍNCIA DE MATO GROSSO
}

\author{
Maria das Graças Campos ${ }^{1}$ \\ https://orcid.org/0000-0003-3096-2588 \\ Marlene Gonçalves ${ }^{2}$ \\ https://orcid.org/0000-0002-4506-184 \\ Maria de Lourdes F. Castrillon ${ }^{3}$ \\ https://orcid.org/0000-0003-4797-880X
}

RESUMO: Trata-se de um estudo que procura destacar a construção dos discursos objetivados sobre as mulheres do século XIX na província de Mato Grosso. Elas foram personagens com significativa relevância na história, que permaneceram no anonimato e ganharam destaque nas narrativas, refletindo o olhar eurocêntrico dos colonizadores e legitimando suas expressões, que revelou uma visão estereotipada das brasileiras. Em relação à metodologia, optou-se pela pesquisa documental. Para tanto, os pequenos fragmentos narrativos dos trajetos e das viagens de Francis Castelnau e de Hercule Florence são indícios que subsidiam a proposta deste texto, que contam, ainda, com a formação sociocultural, a ideologia dos viajantes e os interesses das viagens, que devem ser considerados para escapar das obviedades e dos conceitos generalizantes. Dessa forma, os relatos dos viajantes são memórias de grande significado para as produções acadêmicas e podem ser utilizados como suporte didático na sala de aula, porém é necessário analisar o contexto social e histórico.

PALAVRAS-CHAVE: viajantes, mulheres, Mato Grosso.

\section{WOMEN IN THE REPORTS OF FOREIGN TRAVELERS IN THE NINETEENTH CENTURY IN THE PROVINCE OF MATO GROSSO}

ABSTRACT: This is a study that seeks to highlight the construction of objectified discourses about women in the nineteenth century in the province of Mato Grosso.

1 Doutora em Políticas Públicas e Formação Humana-UERJ. Pesquisadora integrante do grupo LER: Laboratório Educação e República- UERJ/ Rio de Janeiro, Brasil. professoramatogrosso@gmail.com

2 Doutora em Educação pela Universidade Estadual de Campinas - UNICAMP. Professora do Curso de Pedagogia /UFMT em Cuiabá, Mato Grosso, Brasil. E-mail: gochatram@uol.com.br.

3 Mestre em História pela - UFMT. Doutoranda do Programa de Pós-Graduação em Estudos de Cultura Contemporânea -ECCO - UFMT/ Mato Grosso, Brasil.Email:mary_lourdes1996@hotmail.com.

Rev. Fac. Educ. (Univ. do Estado de Mato Grosso), Vol. 35, Ano 20, № 1, p. 195-212, jan./jun, 2021 (Epub Ahead of Print 31 maio, 2021 ). 
They were characters with significant relevance in history, who remained anonymous and gained prominence in the narratives, reflecting the Eurocentric look of the colonizers, and legitimating their expressions, which revealed a stereotypical view of Brazilian women. As for the methodology, we opted for documentary research. To this end, the small narrative fragments of the journeys of Francis Castelnau and Hercule Florence are indications that subsidize the proposal of this text, which also counts on the sociocultural background, the ideology of the travelers and the interests of the trips, which must be considered to escape the obviousness and the generalizing concepts. Thus, travelers' accounts are memories of great significance for academic productions and can be used as didactic support in the classroom, but it is necessary to analyze the social and historical context.

KEYWORDS: travelers, women, Mato Grosso.

\section{LAS MUJERES EN LOS INFORMES DE LOS VIAJEROS EXTRANJEROS EN EL SIGLO XIX EN LA PROVINCIA DE MATO GROSSO}

RESUMEN: Este es un estudio que busca resaltar la construcción de discursos objetivos sobre las mujeres del siglo XIX en la provincia Mato Grossense; personajes de significativa relevancia histórica, que permanecieron anónimas y ganan protagonismo en las narrativas, reflejando el eurocentrismo de los colonizadores y legitimando sus expresiones, revelando así una visión estereotipada de las brasileñas. Como opción metodológica, optamos por la investigación documental. Para ello, pequeños fragmentos narrativos de los viajes de Francis Castelnau y Hercule Florence son indicaciones que subsidian la propuesta de este texto, la formación social y cultural, la ideología de los viajeros y los intereses del viaje, que deben ser considerados para escapar a la obviedad y a los conceptos generalizadores. De esta manera, los relatos de los viajeros son recuerdos de gran importancia para las producciones académicas y pueden ser utilizados como apoyo didáctico en clase, pero es necesario analizar el contexto social e histórico.

PALABRAS-CLAVE: viajeros, mujeres, Mato Grosso. 


\section{Introdução}

Os debates historiográficos sobre as mulheres ganharam relevância a partir da década de 1970, com as mudanças políticas, econômicas e sociais que ocorreram, mais precisamente, no campo das pesquisas. No sentido científico da abordagem, destaca-se que a história do Brasil, no século XIX, buscou enfatizar as tradições de um passado homogêneo, com feitos gloriosos de célebres personagens masculinos, priorizando a política factual, na qual os personagens como os escravos, as mulheres e os trabalhadores pobres ficaram excluídos das páginas da historiografia. Essa abordagem também influenciou o ensino da história, uma vez que prevaleceram os temas dos heróis políticos e houve a ausência de temas sociais.

Tal visão começou a mudar somente na década de 1980, com a História Nova, cuja raiz originária encontrava-se na revista Escola dos Analles, fundada em 1929, por Lucien Febvre e Marc Bloch, que propunham uma narrativa histórica na qual englobava outras fontes, outros sujeitos e novas áreas interdisciplinares, as quais deram origem às áreas de investigação historiográfica da antropologia, da mulher, da escrita, do corpo, da criança, entre outros.

Essas novas áreas de investigação suscitaram o registro de uma narrativa a partir de uma variedade de fontes documentais, tais como: escritas orais (cartas, diários) e iconografia, documentos esses que ganharam relevância nas pesquisas por abarcarem variados assuntos, entre eles, a história das mulheres.

A título de exemplo, utilizamos, neste artigo, os relatos produzidos no século XIX por Hercule Florence e Francis Castelnau (1997), cientistas sociais franceses que estiveram no território mato-grossense.

No século XIX, um dos projetos políticos da Coroa Imperial, segundo Ilmar Mattos, era o de manter os olhos na Europa, o que significava erigir um império semelhante ao dos estados europeus, isto é, um modelo de nação civilizada e, ao mesmo tempo, manter os pés na América, protelando as negociações com os britânicos sobre a extinção do tráfico negreiro. O objetivo era manter a unidade territorial que se consolidou por meio de inúmeras estratégias políticas (MATTOS, 1998, p. 12). Dessa forma, salientamos que as expedições científicas dos viajantes e as atividades artísticas foram incentivadas pela família real.

Nessa conjuntura política colonizadora, era necessário marcar e demarcar o território, a vasta área de matas gigantescas e a população, que, aos olhos da família real, precisava ser "civilizada", para, enfim, explorar as riquezas naturais. Assim, segundo Ilmar Mattos (1998), a monarquia era considerada a 
flor exótica na América desse império. Na época, as viagens eram feitas pelos rios, sendo este o meio mais fácil e moderno, uma vez que a modernidade chegava pelas águas, via navegação fluvial.

Nesse contexto, os viajantes estrangeiros estiveram presentes no território brasileiro por meio de expedições científicas, em que descreviam a natureza da terra e dos rios, cachoeiras e afluentes, bem como a população, sendo vista sob um olhar europeu. Por outro lado, não se pode desconsiderar que os relatos dos cientistas sociais estrangeiros contribuíram com a historiografia brasileira, especialmente para melhor compreensão do passado.

Segundo Martins (2014, p. 44), os viajantes eram homens dotados de interesses científicos e comerciais ou eram curiosos que embarcavam na viagem para adentrar esse "Novo Mundo", cujo momento foi marcado pelas ciências naturais, que iniciaram sua profissionalização e especialização, e pela fragmentação do conhecimento, a qual se fazia necessária para conseguir abarcar tantas explicações.

Os viajantes eram pessoas de ambos os sexos, de classes sociais variadas de profissão e formação intelectual diversificada, que descreveram os aspectos do Brasil por meio de crônicas, relatos de viagem, correspondência, memórias, diários e álbuns de desenhos (GASPAR, 2004). Destaca-se, também, que a documentação estudada menciona as riquezas naturais, o cotidiano e as personagens, descrevendo o ambiente, os percursos descritos nas demarcações de seus itinerários e as condições em que foram feitas essas viagens (MARTINS, 2014, p. 44).

Para a mesma autora, os relatos dos viajantes mostram a superação de obstáculos, a subida de rios e o percurso nas estradas, abrindo picadas e cruzando pantanais (MARTINS, 2014). A descrição do meio ambiente e das riquezas naturais compreende os tipos de moradias, os costumes, os modos de viver, o estilo das fazendas da época e os detalhes dos locais durante o percurso da viagem, como é o caso da narrativa de Castelnau e de Hercule Florence quando passaram pela província de Mato Grosso.

\section{Os relatos dos viajantes como fonte de estudo da história}

Os relatos dos viajantes como fonte de estudo histórico são utilizados por diversos pesquisadores das mais variadas áreas, como História, Literatura, Geografia, Antropologia, entre outras, pois oferecem subsídios tanto nos estudos do cotidiano quanto nos de gênero ou de grupos sociais.

Vale lembrar que, nos relatos apontados pelos viajantes europeus, 
os conceitos apresentados, geralmente, eram díspares quanto à alteridade e à equidade. Ao utilizarmos essas fontes, é necessário particularizar o lugar social dos viajantes e decifrar o momento histórico em que as documentações foram elaboradas.

Assim, segundo Chartier (1999), o mundo é permeado pelas representações, que são constituídas por práticas sociais, as quais, por sua vez, produzem imagens, assim como as narrativas dos viajantes são práticas que perpetuaram imagens construídas em determinado tempo histórico e espaço.

Os manuscritos elaborados pelos estrangeiros e cientistas sociais são documentos organizados e localizados no Arquivo Público de Mato Grosso (APMT), que recebem tratamento adequado, são acessíveis e fartos. Cabe ressaltar que esses materiais ainda não estão sendo utilizados na educação básica, embora deveriam ser, uma vez que se trata de uma ferramenta poderosa a ser aplicada na sala de aula, ainda que os relatos aparentem ter estereótipos eurocêntricos.

Destaca-se que alguns dos relatos desses cientistas estrangeiros também constituem obras impressas e difusas no mercado editorial, pois, para Le Goff, "cada época fabrica mentalmente a sua representação do passado histórico" (LE GOFF, 1994: 26).

Dessa forma, podemos dizer que os relatos dos viajantes do século XIX são documentos importantes, pois abarcam variados assuntos e temáticas do período. Embora prevaleça um olhar estigmatizado de acordo com a visão da época, é imprescindível salientar que os relatos dos viajantes atuaram na mentalidade de uma sociedade, podendo-se dizer, ainda, que as narrativas dos viajantes estrangeiros eram de acordo com os seus interesses. Muitas das escritas de viagem foram editadas e tiveram boa recepção do público editorial europeu, logo, o mercado editorial também pode ser identificado como um interesse presente na escrita de viagem.

\section{O olhar a respeito da mulher}

São vários fragmentos que podem ser utilizados nas pesquisas, como o caso das mulheres, que, diante do sistema patriarcal, ficavam subalternas ao mundo masculino e ofuscadas por esse público, com estratégias de sobrevivência, elas construíram sua participação na história. Ainda que a invisibilidade da figura feminina fosse naturalizada pela sociedade da época, é possível torná-la visível pela documentação, pois as narrativas destacam as personagens femininas e demonstram como elas eram inseridas no sistema 
escravista e mantinham as formas de sobrevivência.

Pode-se considerar que, durante séculos, a mulher, enquanto sujeito histórico, foi silenciada na historiografia, cujo paradigma foi alterado a partir da História Nova, ocorrida na década de 1980, ou seja, tornou-se possível escrever uma história que incluísse as mulheres, demonstrando que, apesar do "silêncio das fontes" ou, até mesmo, da forma como foram representadas pelos homens, elas participaram do processo histórico ao longo do tempo (CORREIA, 2009, p. 3).

Nessa direção, a construção historiográfica produziu um discurso que apresenta a figura feminina na condição de submissa ao homem, descrita com visibilidades negativas, assim como nos manuscritos dos viajantes estrangeiros.

De fato, a mulher, tanto no período colonial quanto no imperial, nas primeiras décadas do século $X X$, teve suas funções sociais ofuscadas, mas foi alvo dos manuscritos dos cientistas estrangeiros. A abertura de espaço para que a mulher galgasse um posto de trabalho além dos afazeres domésticos caracterizou-se como mais um instrumento de discriminação dos sexos.

Assim, a ideia de que a função da mulher como professora seria um prolongamento das funções maternas, com salários inferiores, além de sua exclusão do ensino secundário, configuravam-se, mais uma vez, como uma limitação às oportunidades de acesso ao conhecimento de forma igualitária em relação aos homens.

Na análise que faz a respeito da instrução feminina na colônia e no império, Saffioti (2013) afirma que a presença dos jesuítas repercutiu, em curto prazo, uma força social construtiva quando se iniciou, nas primeiras letras, uma parcela masculina da população. Mas, no caso das mulheres, não houve um bom impacto enquanto não foram propiciados instrumentos de libertação, já que a ordem esbarrava com a autoridade de um senhor chefe de uma família patriarcal, na qual ele dominava a mulher e os filhos. Nesse contexto, os meninos eram doutrinados nas escolas e as meninas, nas capelas e igrejas.

No Brasil do século XIX, surgiram algumas oportunidades de educação laica para as mulheres, sendo que as outras oportunidades podiam ser consideradas pontuais e de pouca abrangência para garantir a escolarização delas.

Segundo Saffioti, estas iniciativas não poderiam ser consideradas o que, modernamente, se entende por um colégio. Eram pensionatos nos quais as senhoras portuguesas e francesas ensinavam costura, bordado, religião, rudimentos da aritmética e da língua nacional. (SAFFIOTI, 2013, p. 191).

Conforme Stamatto (2018), no decorrer do século XIX, houve um aumento gradual dos efetivos femininos na rede escolar. Estatisticamente, havia 
uma menina para cada três alunos nas escolas públicas ao final daquele século.

A criação das escolas "mistas" regidas por professoras no final do Império fez aumentar significativamente o contrato de mulheres. Houve a regulamentação da carreira do magistério durante os governos provinciais e o estabelecimento de escolas normais para a formação de professores(as) nas últimas décadas do período imperial, que passaram a ser frequentadas quase que exclusivamente por moças. Houve também a implementação dos grupos escolares, na primeira década do século $X X$, onde o corpo docente, neste momento, já era predominantemente feminino. (STAMATTO, 2018, p. 10).

Conforme LEONCY (2013), somente em meados dos anos 1970 e durante os anos 1980, as discussões evoluíram para além dos debates a respeito das diferenças, enfocando a questão da igualdade e de gênero. Essas pautas, contribuíram para a inclusão socioeducativa das mulheres brasileiras, tendo dentro dos movimentos feministas uma contribuição decisiva para refletir sobre a inserção da mulher no mercado de trabalho, colaborando, assim, para a identificação de seus valores e representações, suas lutas e proposições políticas (LEONCY, p. 17, 2013).

$\mathrm{Na}$ atualidade, as propostas curriculares, por meio dos temas transversais, permitem a discussão sobre temas como religião, mulheres e multiculturalismo, que, até então, eram excluídos da prática educacional e da pesquisa, numa abordagem no meio escolar distante dos impregnados conceitos eurocêntricos. Essa variada documentação, que contém escritas sobre a mulher, pode ser utilizada como suporte didático na sala de aula, porém é necessário analisar o contexto social e histórico, bem como a formação social e cultural, a ideologia dos interesses e dos conceitos generalizantes, buscando o caminho da decolonização.

\section{Viajantes na província de Mato Grosso}

Para compreender os aspectos dos costumes e conceitos, este estudo aborda algumas peculiaridades do percurso de um viajante que esteve na província de Mato Grosso no século XIX: o francês Hercule Florence ${ }^{4}$. Ele veio para o Brasil em 1824, com objetivos de empreender a expedição científica, saindo do rio Tietê, em São Paulo, até a região do Amazonas, e ficou respon-

4 Hercule Florence nasceu em 1804, foi um desenhista que logo se engajou na expedição do naturalista alemão Langsdorff.

Rev. Fac. Educ. (Univ. do Estado de Mato Grosso), Vol. 35, Ano 20, № 1, p. 195-212, jan./jun, 2021 (Epub Ahead of Print 31 maio, 2021 ). 
sável pela construção da documentação cartográfica. Essa expedição durou quatro anos (1825 a 1829).

Ao passar pela vila de Cuiabá, em 1827, Hercule Florence narrou os costumes dos habitantes e afirmou que, naquele momento, havia uma média de 6 mil habitantes na cidade, sem contar os índios mansos e, muito menos, os bravios. Para ele, as pessoas que vieram para cá foram atraídas pelo ouro e, logo que conseguiram, partiram para um país mais "civilizado", enquanto os que ficaram foram envolvidos por prazeres grosseiros com amásias.

Já no século XIX, quando Florence observou e analisou os costumes da população, reportou-se a outro tempo histórico ao dizer que muitas pessoas vieram para Cuiabá à procura da mineração, de modo a justificar os hábitos incivilizados. Dizia Florence que, em Cuiabá, os casamentos eram poucos:

\begin{abstract}
As mulheres de classe média e, sobretudo, inferiores, são muito livres nas suas conversas, modos e costumes. Além do contínuo exemplo da licença geral e quase desculpada, recebem pernicioso influxo do contato dos escravos, negros e negras, cujas paixões violentas não veem peias a sua expansão. A fidelidade conjugal é, muitas vezes, falseada. Apesar de temerem os maridos e considerá-los como amos e senhores, sabem perfeitamente enganá-los. (FLORENCE, 1997, p. 147)
\end{abstract}

A respeito das mulheres, Florence salientou que elas eram "livres nas conversas" e que havia conhecido uma que, embora fosse falante, era "civilizada". Ao retratar os costumes dos habitantes, Florence deu visibilidade às mulheres, contudo enfatizou que os valores negativos eram universalizados às mulheres, independentemente da classe ou posição social.

Naquele momento histórico, segundo o ideal social, era impreterível que a sociedade brasileira buscasse se equiparar a nações civilizadas como França e Inglaterra, e, para isso, no entendimento das autoridades políticas, era preciso que a população cultivasse costumes europeus.

Norbert Elias (1990), em sua obra O Processo Civilizador, argumenta que os viajantes tinham ideias iluministas e educação a partir de um discurso moralista e religioso. No entanto, havia uma contradição: o Brasil possuía um sistema escravista, que classificava e enquadrava os grupos sociais, criando espaços de exclusão e formas de viver e de fazer.

Diante dessa conjuntura, é preciso desconstruir a ideia de que o sistema escravista era responsável pelos hábitos "perniciosos", cuja responsabilidade recaía nas ações humanas, mais precisamente, dos negros, conforme 
evidencia o documento. A naturalização sobre os escravos foi difundida em todos os relatos oficiais da época e, especialmente, dos viajantes estrangeiros, conforme afirma Florence:

As moças filhas de pobres não pensavam em casamento a não ser quando o homem tivesse um dote, e como não trabalhavam eram arrastadas pela vida licenciosa. Todavia, apesar de pertencerem a todos, nunca mostraram as baixezas e ganâncias das mulheres públicas europeias. (FLORENCE, 1997, p. 147)

Entretanto, antes de chegar à Vila Maria do Paraguai (hoje Cáceres), passou pela fazenda Jacobina. Na época, uma das mais ricas propriedades da província de Mato Grosso. Segundo um dos relatos, após uma refeição, Florence, ao entrar num primeiro pavimento da fazenda, deparou-se com mais de cem pessoas entre escravos e gente alforriada, sendo a maior parte do sexo feminino.

Para espanto do viajante, o comando dessa propriedade estava sob a responsabilidade de uma mulher, "cujo pescoço estava envolto de muitas voltas de colares de contas grossas de ouro". Sobre a proprietária da fazenda, o francês não emitiu juízo de valor eurocêntrico, descrevendo-a assim:

O que havia de notável era que essa mulher, tão corpulenta e que mostrava ter cinquenta anos, andava e mexia-se com agilidade de uma garrida mocetona. Sua fisionomia, seu olhar e boca exprimiam simultaneamente a energia, a franqueza e a bondade. Todos os escravos e agregados a estimavam tanto quanto a temiam, sendo com efeito a mãe de toda redondeza, principalmente pelos cuidados com que tratava os enfermos e pelos socorros que com pródiga mão distribuía aos necessitados. (FLORENCE, 1997, p. 184)

Segundo Florence, nessa propriedade, havia, em média, uns 200 escravos, de ambos os sexos, e umas 60 crianças. Existia também, na mesma proporção dos escravos, gente forra, entre agregados, crioulos, mulatos e índios. Esse autor descreveu, ainda, com muitos detalhes, os povos Bororos, destacando os adereços, a estatura, os cabelos, o corpo, os modos de viver e de ser e os movimentos (FLORENCE, 1997, p. 184).

As descrições das narrativas quase sempre acompanhavam os desenhos, que, entre eles, estavam os de várias mulheres indígenas: 
Mulher carregando, além de uma criança a cavalo sobre os ombros, um cesto suspenso às costas por uma embira que passa pela testa. Esses fardos a obrigam a curvar a cabeça e o corpo, e não lhes permite levantar uma fronte altiva, como os injustos homens de sua horda. Os cabelos cortados do mesmo jeito dos homens são mais curtos e em desordem. Não tem como único ornamento senão os crescentes nas orelhas. (FLORENCE, 1997, p. 197)

Com base nessas afirmações, fica evidente o olhar de Florence (1997) ao exemplificar as características humanas da submissão feminina na convivência entre os povos Bororos, quando os fardos impedem a mulher de revelar uma face altiva, como pode ser observada na figura abaixo:

Figura 1 - Imagem dos índios Bororos

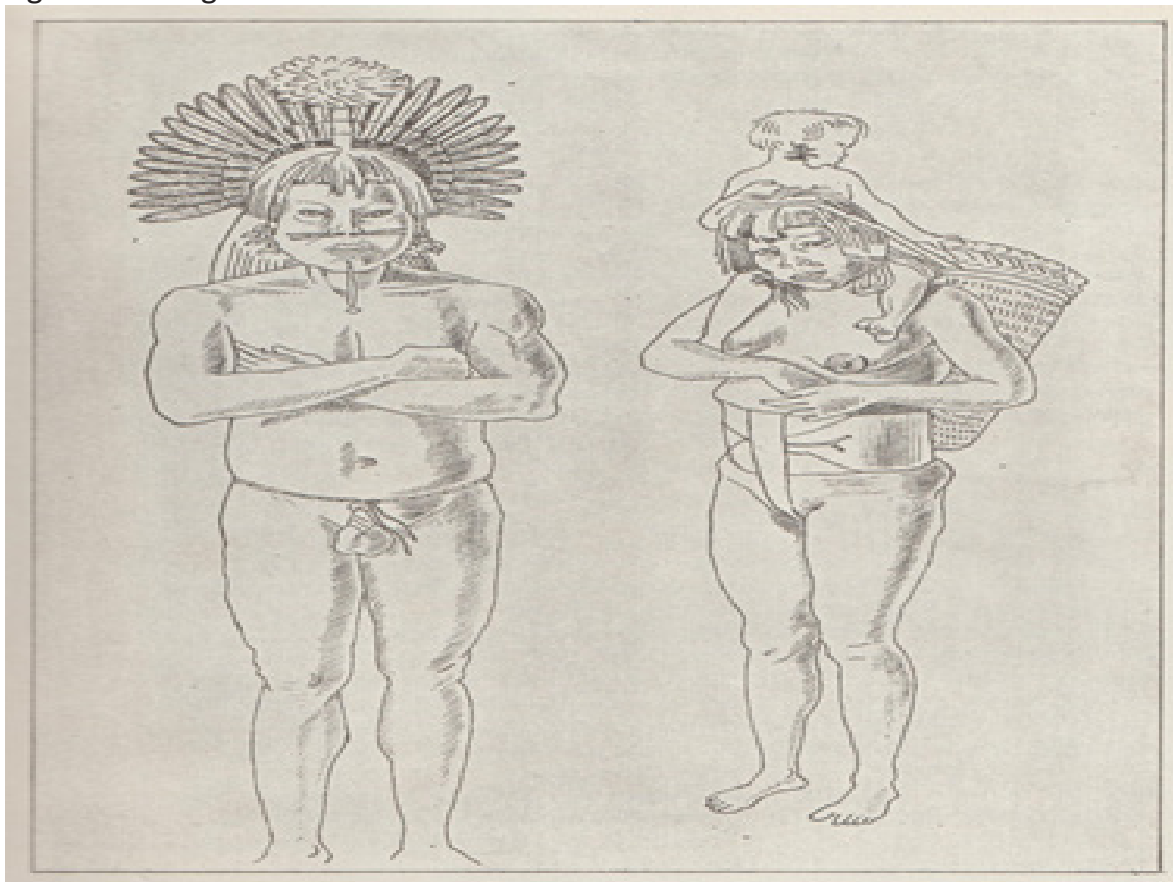

Fonte: FLORENCE. Hercules. 1997, p. 193.

Florence (1997) informou também que os povos Bororos, por volta de uns dez anos antes dessa estadia na localidade, eram mais "selvagens" por- 
que matavam escravos e destruíam plantações. Por essa razão, o proprietário da fazenda, João Pereira Leite, matou, em média, uns 450 deles e manteve alguns na condição de prisioneiros sujeitados ao trabalho forçado. Além disso, destacou que era comum aquela gente ingerir aguardente.

Nesse enfoque dos estudos de Florence (1997), percebe-se a memória de um tempo não vivido pelo viajante, contada pelo dono da propriedade, que não deixa de naturalizar o conceito referente à população nativa como "selvagem", o que denota um estereótipo inerente à situação colonizadora e, de certa forma, invasora, a que ficavam submetidos os índios da região, os quais, por circunstâncias, perdiam também a vida e o território.

Vale ressaltar que, na sociedade patriarcal, havia o medo dos ataques indígenas, pois era acirrada a luta em busca de espaço e fluía a ideia de "civilizar" os índios, de modo a treiná-los para os serviços, estabelecendo-os em lugares onde pudessem ser "cuidados" (MARTINS, 2014, p. 64).

Na obra, foi evidenciado o destaque à Vila de Albuquerque e às variedades de etnias indígenas, como os Guaicurus, Guanás e Quinquinaus, conforme a figura a seguir:

Figura 2 - Índio Guaicuru
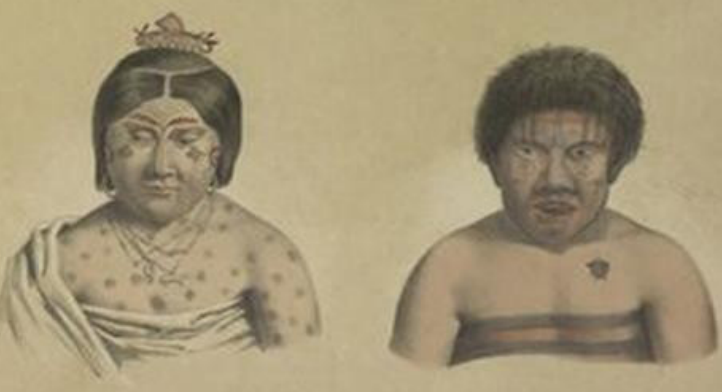

Fonte: https://br.pinterest.com/pin/737183032726068151. Acesso em: $1^{\circ}$ mar. 2019. 
A imagem é da etnia Guaicuru, referente à expedição da América de 1843-1857, realizada por Castelnau, cujo percurso incluiu Rio de Janeiro, Lima (Peru), Pará e Mato Grosso, mais precisamente, a cidade de Corumbá, localizada na parte sul do estado, que faz fronteira com a Bolívia. Essa imagem faz parte da exposição virtual Povos Indígenas, do Arquivo Nacional.

Francis Castelnau, que partiu de Paris, em 22 de abril de 1842, para uma expedição científica, ocupava-se dos estudos de Botânica, Geologia e Zoologia. Nessa expedição, passou pelo Brasil, especificamente, pelas províncias do Rio de Janeiro, Minas Gerais, Mato Grosso, Goiás, Amazonas e Pará, e esteve, ainda, em Assunção (Paraguai) e na Bolívia (CASTELNAU, 1949).

Após esse trajeto, passou pelo Amazonas, chegando ao Pará. Ao adentrar a província de Mato Grosso, andou por Vila Maria e Vila Bela da Santíssima Trindade, até chegar à Bolívia (CASTELNAU, 2000).

Ao chegar à capital da província de Mato Grosso (Cuiabá), Castelnau relatou que as ruas eram retas, largas, bem calçadas e com lampiões, e as casas eram de sobradinhos, semelhantes às europeias. Nesse relato, são também mencionadas as visitas feitas ao Arsenal de Guerra, que possuía fuzis e canhões, ao bairro do Porto e à igreja, nas quais havia a presença das mulheres, nesse caso, destacando-se a mulher negra.

Em Cuiabá os costumes são ainda piores do que nas outras
partes do Brasil central, é desagradável ser forçado a declarar
que, deste particular, o mau exemplo é dado pelos padres, os
quais não se arreceiam para satisfazer as suas brutais paixões,
de usar de a influência conferida pela sua posição, como ainda
de pôr ao serviço delas as cerimônias mais santas da religião.
Há frequentes desavenças, não raro resolvidas a faca. A defesa
policial é insuficiente para impedir que ela se entregue freneti-
camente ao batuque e às mais vergonhosas orgias. (CASTELNAU,
2000, p. 320)

Nessa narrativa, o viajante também descreveu detalhes sobre a alimentação, destacando os artigos comerciais como feijão, carne seca, guaraná (produto trazido do Amazonas), açúcar, cavalos e bois. Entre esses, destacou-se o preço do escravo, que valia, em média, 700 a 800 mil réis (CASTELNAU, 2000, p. 320).

No trajeto de sua viagem, ao passar por Vila Maria, descreveu a população, que não ia além de 500 ou 600 pessoas. Toda a freguesia da qual a vila é o centro não tem mais de 1.800 habitantes de todos os matizes, inclusive, com cerca de 200 escravos. Quando passou pela fazenda Caiçara, no dizer do 
viajante, a propriedade "era distante de Vila Maria uma légua". Assim diz ele:

A fazenda fica situada um tiro de canhão a noroeste da baía. Conhecemos ali uma negra albina, de pele cor de rosa e cabelos louros como os de uma europeia, muito embora fosse filha de um negro da Costa d'África, com uma preta da terra. Fenômenos desta espécie não são raros no Brasil. (CASTELNAU, 2000, p. 425)

Reafirma-se que, no século XIX, prevalecia uma sociedade escravocrata, cuja ideologia científica fortalecia os discursos racistas pelas teorias evolucionista e darwinista, que naturalizavam as diferenças (SCHWARCZ, 2000, p. 65).

Segundo Kabengele (2003), a teoria científica serviu mais para justificar o sistema de dominação e de exclusão do que para explicar a classificação humana. Diante das incessantes explicações científicas da época, o racismo acentuado impregnou naturalizações sobre a discriminação racial, desvalorizando a identidade desse segmento social. Em relação aos indígenas, Castelnau registrou:

Os índios são bem constituídos, mas ninguém pode calcular até que ponto vai a sua sordície, pintam-se de vermelho por meio de urucum e vivem cheios de feridas e outras doenças repugnantes. Os homens andam nus, exceção feita de um cordel de acuri passado à volta da cintura. As armas que usam são pesadas e consistem num arco de mais de dois metros de comprimento e flechas de tamanho quase equivalente, terminadas em agudíssima ponta feita de bambu. As mulheres geralmente trazem um pequeno pedaço de pau no lábio inferior e, como única vestimenta, usam em torno dos rins uma espécie de colete, feito de jatobá. Essa peça é pintada de preto, com exceção de uma faixa muito estreita que passa debaixo das pernas, e a qual se conserva a cor natural (CASTELNEAU, 2000, p. 426).

Os indígenas mencionados pelo francês são os cabaçais, sendo evidente o olhar estereotipado do viajante sobre o grupo étnico, dando a ideia de que os adereços, as armas e a vestimenta deles são objetos estranhos. No retorno da viagem, relata que, alguns meses depois, ao passar pelo mesmo aldeamento, observou um cenário de fome e muita miséria: no chão cheio de lixo, de pedaços de osso, de coco e raízes, via-se deitada uma rapariga ainda moça, mas reduzida a um estado de magreza que é impossível imaginar, todo seu corpo estava na mais espantosa sujeira, as pernas não tinham mais movimentos. (Idem, op. cit., 427) 
Em 10 de junho de 1845, a comitiva de Castelnau (1949) chegou à Vila Bela da Santíssima Trindade e foi recepcionada pelo filho do chefe militar da praça. As primeiras observações descritas acerca de Vila Bela se referem à comparação entre a cidade e Cuiabá. Porém, neste artigo, é fundamental destacar que a observação mais relevante seria a descrição encontrada na obra a respeito das mulheres vila-belenses, ao participar de um jantar no palácio, assim descrito:

Num dos lados da mesa estavam agrupadas umas doze mulheres muito bem vestidas, quase todas mulatas e com aparência de grande acanhamento, em face dos estrangeiros. [...] As damas tinham se conservado em silêncio toda a refeição e, esta acabada, desapareceram para não mais voltar. Foi primeira vez, desde que tínhamos saído do Rio de Janeiro que vimos as mulheres tomarem lugar à mesa (CASTELNAU, 1949, p. 367).

Infere-se, em primeiro lugar, que a presença feminina à mesa surpreendeu o viajante, tanto que ele destaca que, durante o seu percurso, configurou-se um fato inédito. Em segundo lugar, nota-se ainda, nas entrelinhas, o fator de estranhamento por serem mulheres negras, o que não foi observado nem na sua passagem pela corte. Na descrição do jantar, outros sinais do desprestígio feminino em relação aos homens são captados pelos olhos dele, como o fato de elas permanecerem em silêncio o tempo todo.

Como não havia assentos para todos na mesa, as mulheres sentaram de duas ou três nas cadeiras, e em até três mulheres comiam no mesmo prato e com as mãos. No entanto as damas ficaram silenciosas e uma vez acabada a refeição desapareceram do cenário (CASTELNAU, 1949, p. 367).

Já por outro lado, Gonçalves (1995) destaca que as mulheres vila-belenses nunca ficaram à margem dos acontecimentos e dos problemas da cidade. Conforme a autora:

Essa visibilidade da mulher vila-belense advém de seu engajamento no cotidiano da comunidade, mesmo que às vezes seja aparentemente à sombra do homem, como ocorre na família, onde a chefia é formalmente um papel do homem, mas a muIher tem direito à voz. Ela participa do comando familiar, não apenas como mãe e esposa, mas como alguém que produz a sobrevivência. (GONÇALVES, 1995, s.d.) 
No período colonial, as mulheres, além de não terem vida pública, na hora das refeições, ficavam na cozinha. No entanto, no século XIX, elas começaram a conquistar um espaço maior. Esse aspecto despertou a atenção do viajante, em sua observação de estrangeiro, pela presença da mulher à mesa na hora da refeição, embora não conversassem.

Do mesmo modo, o viajante narrou aspectos da vida da população de três localidades: Vila Maria, Vila Bela e a vila de Corumbá, que, a partir de 1979, com a divisão de Mato Grosso, passou a pertencer ao novo estado, Mato Grosso do Sul. De acordo com ele, a parte feminina representava a maior parcela da população, pois havia, em Corumbá, um total de 70 pessoas adultas, sendo que 50 eram mulheres (CASTELNAU, 2000, p. 363).

\section{Considerações finais}

Como já foi mencionado, a documentação é valiosa para a produção da pesquisa, bem como é material de grande utilidade para as aulas de História e de Geografia, uma vez que as narrativas detalham os caminhos percorridos pelos viajantes, quais sejam, os rios, a flora e a fauna, descrevendo os ambientes paisagísticos e urbanos das freguesias e vilas, a cultura da população dos escravos e indígenas de várias etnias, as formas de sobrevivência e os modos de fazer.

Pelos itinerários percorridos, podemos abarcar diversas temáticas e objetos de estudo. As mulheres mostradas na documentação eram pobres, da elite, negras, brancas e índias, às quais foram atribuídos conceitos eurocêntricos e generalistas, com exceção da proprietária da fazenda Jacobina.

Apesar de alguns avanços, percebe-se que, atualmente a sociedade brasileira vem reproduzindo a afirmação de aspectos educacionais excludentes, que reafirmam a superioridade do homem no trabalho e na vida em sociedade, quando muitas mulheres ainda recebem salários inferiores para exercerem trabalhos iguais e muitas outras permanecem com baixa renda ao atuarem em profissões que possibilitam uma remuneração digna.

Para analisar essa fonte documental, é preciso considerar a formação sociocultural do cientista social ocidental, ou seja, utilizando as palavras de Michel de Certeau (1982): "é preciso perceber o lugar social de quem fala, do que fala e para quem fala, e em que momento fala."

Obviamente, isso não significa que sejam afirmações absolutas; o que tentamos nesta "operação historiográfica" é dar unidade ao texto, articulando os documentos com as questões de ensino e dos procedimentos metodológi- 
cos. Desta forma, pode ser possível enfocar esse passado com outros olhares e com múltiplas interpretações.

Dessa forma, na atualidade, o estudo pode proporcionar análises e fomentar debates sobre a história de Mato Grosso, podendo estimular o surgimento de outras reflexões e olhares a respeito do objeto da pesquisa.

\section{Referências}

BRAUDEL, Fernand. História e Ciências Sociais. Lisboa: Editorial Presença, 1986.

CASTELNAU, Francis. Expedição às regiões centrais da América do Sul.Tomo I e II,São Paulo.Companhia Editora nacional de São Paulo.1949

CASTELNAU, Francis. Expedição às regiões centrais da América do Sul. Belo Horizonte / Rio de Janeiro: Itatiaia, 2000.

CASTRO, Maria Inês M. \& GALETTI, Lylia S.G. Histórico dos usos da biodiversidade em Mato Grosso. In: Castro, Carlos F.A. (org.). Diagnóstico do setor florestal em Mato Grosso. Brasília, 1994.

CERTAU. Michel. A escrita da História. tradução de Maria de Lourdes Menezes ; revisão técnica [de] Arno Vogel. - Rio de Janeiro: Forense Universitária, 1982.

CHARTIER, Roger. A história cultural: entre práticas e representações. Lisboa: Difel, 1999.

CORREIA. Janaina Santos. Uma contribuição para a escrita da História das mulheres afrodescendentes no Brasil. Revista Feminismos, v. 1, n. 3, set.-dez./2018. Disponível em: www.feminismos.neim.ufba.br. Acesso em: 9 abr. 2018.

FLORENCE, Antoine Hercule Romuald. Viagem fluvial do Tietê ao Amazonas de 1825 a 1829. Brasília: Edições do Senado Federal, 2002.

FLORENCE, Antoine Hercule Romuald. Viagem fluvial do Tietê ao Amazonas de 1825 a 1829. Brasília: Edições do Senado Federal, 1997.

FREYRE, Gilberto. Casa-Grande \& Senzala. 41. ed. Rio de Janeiro: Record, 2000.

FREYRE, Gilberto. Casa-Grande \& Senzala. 41. ed. Rio de Janeiro: Record, 2000. 
GASPAR, Lúcia. Viajantes (relatos sobre o Brasil, século XVI a XIX). Pesquisa Escolar Online, Fundação Joaquim Nabuco, Recife. Disponível em: http:// http://basilio.fundaj.gov.br/pesquisaescolar/. Acesso em: 10 nov. 2018.

GASPAR, Lúcia. Viajantes (relatos sobre o Brasil, século XVI a XIX). Pesquisa Escolar Online, Fundação Joaquim Nabuco, Recife. Disponível em: http://basilio.fundaj.gov.br/pesquisaescolar/index.php?option=com_content\&view=article\&id=131\&ltemid=1 Acesso em: 6 ago. 2009.

GONÇALVES, Marlene. A mestra sempre viva: mulher e educação em Vila Bela. Cuiabá: Instituto de Educação, 1995. 164p. Disponível em: http://eh. net/XIIICongress/cd/papers/ 60JochimsReichel320; https://www.geledes. org.br/wp-content/uploads/2014/04. Acesso em: fev. 2019.

LE GOFF, Jacques. História e Memória. 3a ed. Campinas, SP: Editora da UNICAMP, 1994.

LEONCY, Christiane. Mulheres na EJA: questões de identidade e gênero. (Mestrado em Educação) - Universidade Estadual de Campinas, Campinas, SP, 2013.

MARTINS. Dulcinéia Silva. No silêncio dos arquivos: relatos de viajantes que percorreram Mato Grosso (1808-1864). Cuiabá: EdUFMT, 2014.

MATTOS, Ilmar Rohloff. O tempo Saquarema. São Paulo: Editora Hucitec,1998.

MUNANGA, Kabengele. Uma abordagem conceitual das noções de raça, racismo, identidade etnia. Disponível em: https://www.geledes.org.br/wp-content/uploads/2014/04/. Acesso em: 12 fev. 2019.

REICHEL. Heloisa Jochims. Os relatos dos Viajantes como fonte para o estudo de história. Programa de Pós-Graduação em História da UNISINOS - RS, 2008.

RIBEIRO, Darcy. O povo brasileiro: a formação e o sentido do Brasil. São Paulo: Companhia das Letras, 1995.

SAFFIOTI, Heleieth. A Mulher na Sociedade de Classes. Mito e realidade. 3a Ed., São Paulo: Expressão Popular, 2013.

SCHWARCZ, Lilia Moritz. O Espetáculo das Raças - cientistas e instituições no Brasil - 1870-1930. São Paulo: Companhia das Letras, 2001.

STAMATTO, Maria Inês Sucupira. Um olhar na história: a mulher na escola (Brasil: 1549 - 1910). Programa de Pós-Graduação em Educação - UFRN. Disponível em: 
http://sbhe.org.br/novo/congressos/cbhe2/pdfs/Tema5/0539. Acesso em: jul. 2018.

Data de recebimento: 11.04 .2020 Data de aceite: 17.05.2021 